Developmental Biology

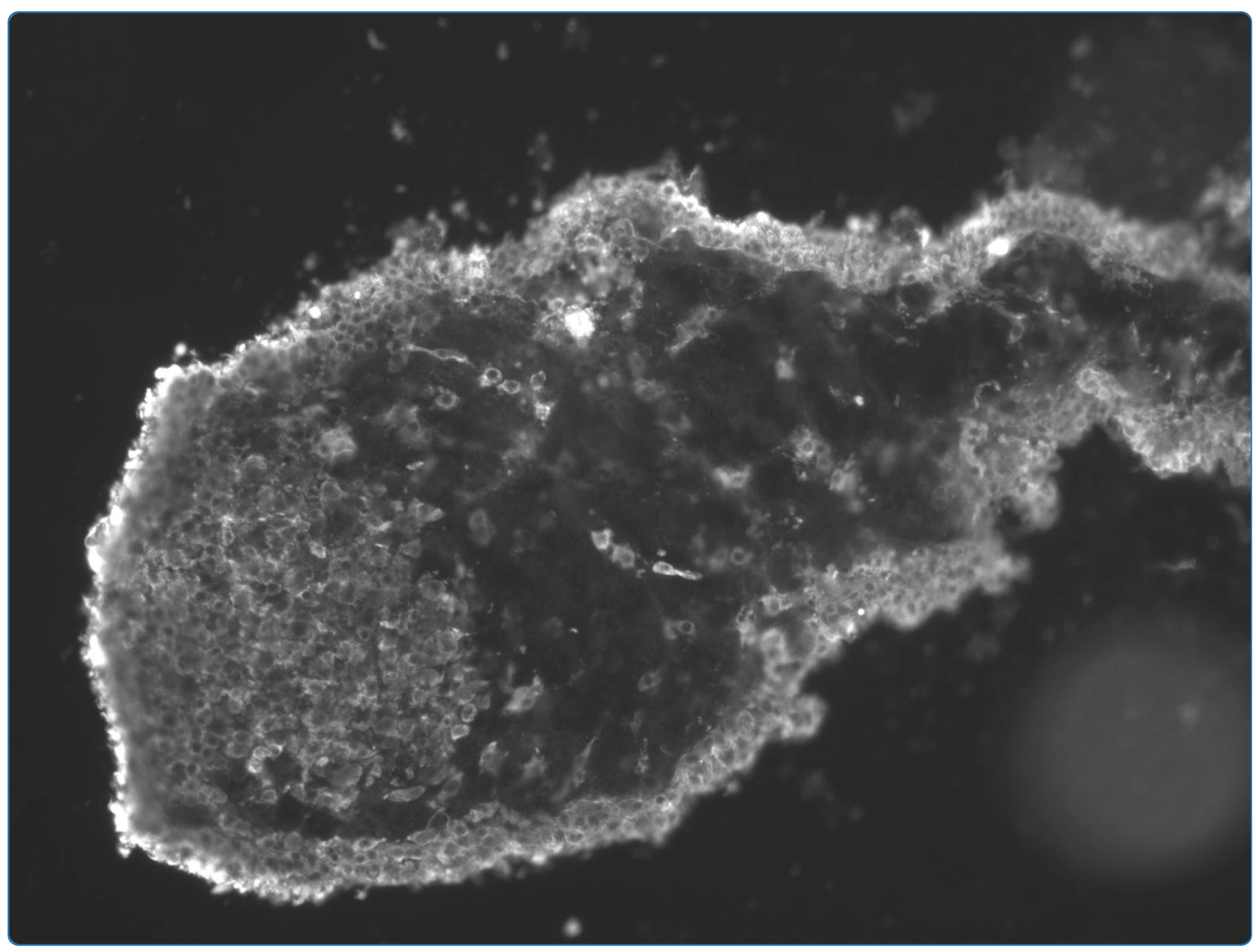

Cell dedifferentiation and epithelial to mesenchymal transitions during intestinal regeneration in $H$. glaberrima

García-Arrarás et al. 


\title{
Cell dedifferentiation and epithelial to mesenchymal transitions during intestinal regeneration in $\mathrm{H}$. glaberrima
}

\author{
José E García-Arrarás*, Griselle Valentín-Tirado, Jaime E Flores, Rey J Rosa, Angélica Rivera-Cruz,
} José E San Miguel-Ruiz and Karen Tossas

\begin{abstract}
Background: Determining the type and source of cells involved in regenerative processes has been one of the most important goals of researchers in the field of regeneration biology. We have previously used several cellular markers to characterize the cells involved in the regeneration of the intestine in the sea cucumber Holothuria glaberrima.

Results: We have now obtained a monoclonal antibody that labels the mesothelium; the outer layer of the gut wall composed of peritoneocytes and myocytes. Using this antibody we studied the role of this tissue layer in the early stages of intestinal regeneration. We have now shown that the mesothelial cells of the mesentery, specifically the muscle component, undergo dedifferentiation from very early on in the regeneration process. Cell proliferation, on the other hand, increases much later, and mainly takes place in the mesothelium or coelomic epithelium of the regenerating intestinal rudiment. Moreover, we have found that the formation of the intestinal rudiment involves a novel regenerative mechanism where epithelial cells ingress into the connective tissue and acquire mesenchymal phenotypes.

Conclusions: Our results strongly suggest that the dedifferentiating mesothelium provides the initial source of cells for the formation of the intestinal rudiment. At later stages, cell proliferation supplies additional cells necessary for the increase in size of the regenerate. Our data also shows that the mechanism of epithelial to mesenchymal transition provides many of the connective tissue cells found in the regenerating intestine. These results present some new and important information as to the cellular basis of organ regeneration and in particular to the process of regeneration of visceral organs.
\end{abstract}

\section{Background}

In recent years, investigators have shown a renewed interest in regenerative phenomena. In view that many "classical" model system organisms show limited regenerative capacities, research on non-traditional model systems has flourished. Many of these organisms, such as planarians and Hydra, had been studied previously, some for almost three centuries. However, modern cellular and molecular tools have permitted a novel look into these regeneration models and a re-examination of

\footnotetext{
* Correspondence: jegarcia@hpcf.upr.edu

Biology Department, University of Puerto Rico, Rio Piedras 00931, Puerto
} Rico

( 2011 García-Arrarás et al; licensee BioMed Central Ltd. This is an Open Access article distributed under the terms of the Creative Commons Attribution License (http://creativecommons.org/licenses/by/2.0), which permits unrestricted use, distribution, and reproduction in any medium, provided the original work is properly cited. the cellular and molecular mechanisms involved in the regenerative events [1].

Crucial to the understanding of organ or limb regeneration is identifying the origin of the cells that form the new regenerated structure. Equally important is a related issue, whether the cells undergo dedifferentiation and/or proliferation. Experimental results have shown some similarities and differences among regenerating animal groups. For example, in planarians, regeneration depends on a population of proliferating stem cells, called neoblasts, that can give rise to all cell phenotypes $[2,3]$. In contrast, during newt limb regeneration, cells adjacent to the injury dedifferentiate, proliferate and then give rise to the cells of the regenerating structure $[4,5]$. 
Our laboratory has been active in studying the process of intestinal regeneration using the sea cucumber Holothuria glaberrima as a model system. This species, like many other holothurians, has the capacity to eject its digestive tract under stressful environmental circumstances [6]. The process occurs naturally and can be induced in the laboratory [7]. Following the evisceration process, the animal regenerates the lost digestive tract, which is mainly composed of descending and ascending small intestine and a large intestine. The new intestine is formed at the edge or margin of the mesentery where the eviscerated intestine was previously attached. We have shown that the new intestine forms from a thickening of the mesentery [7]. This thickening forms a solid rod that extends from the cloaca to the esophagus. As regeneration proceeds, cells from the lumen of the esophagus and the cloaca migrate into the intestinal rudiment forming its lumen. Roughly a month after regeneration has begun, a smaller but apparently functional new intestine has formed.

We have investigated the cellular and molecular events that occur during this regenerative organogenesis. Our initial studies showed that intestinal regeneration involved cell division [7], cell migration [8], extracellular matrix remodeling [9] and cell dedifferentiation [10]. Many of these mechanisms are common to regenerative events not only in other echinoderms [11-13], but in most animals with strong regenerative capacities, such as Hydra [14-16], Planaria [2,3], and some amphibians [17]. More recently we have probed the molecular basis of intestinal regeneration. Using gene-by-gene strategies, high throughput sequencing and microarrays we have now identified multiple genes that are associated with the process of intestinal regeneration [18-21].

In our quest for cellular markers that identify cell populations or phenotypes associated with the intestinal regenerative phenomenon, we obtained a monoclonal antibody that labels the intestinal mesothelium. This is a composite tissue in echinoderms, made up of peritoneocytes (or coelomic epithelial cells) and myocytes [22]. Mesothelial cells are known to play a key role in intestinal regeneration [12]. This antibody has now been used to probe the spatial and temporal pattern of previously described cellular events that occur during the first ten days of intestinal regeneration, namely muscle dedifferentiation and cell proliferation. More importantly, by studying the expression pattern of the cells recognized by this novel antibody during the regenerative event we made the surprising discovery that the cells of the mesothelium are ingressing into the underlying connective tissue to give rise to mesenchymal cells within the regenerating structure. This novel phenomenon has not been described in other regenerating echinoderms. Finally, we have integrated the available information into a coherent view of the cellular origins that lead to the formation of the intestinal rudiment.

\section{Results}

\section{Overview of intestinal regeneration}

To understand the results described here, it is necessary to provide background information on the tissue and morphological changes that underscore the regenerative process. Some of these events have been described in previous publications, however, they have never been presented in a cohesive view that shows the sequence of events of early regeneration stages. Tissue labeling with Toluidene Blue provides the tissue/organ level information needed (Figure 1). The quantification of the growth is shown in Figure 2. We have also provided a drawing (Figure 1A) depicting the relationship of the growing rudiment ( $\sim 5$-dpe) to the mesentery and that of the mesentery to the body wall. This figure provides a point of reference for the findings described below.

As has been shown before, the formation of the intestinal rudiment takes place at the free end of the intestinal mesentery. One day after evisceration, epithelial cells covered the cut edge of the mesentery. However, no thickening or any other obvious morphological difference could be observed between the tip and the rest of the remaining mesentery (Figure 1B). The first indication of swelling of the distal mesentery was observed in some animals at day 2 and in all animals by day 3 of regeneration (Figure 1C). The thickening was wider near the edge of the mesentery and became thinner as one moved toward the body wall gradually achieving the width of the rest of the mesentery. This growth of the distal portion of the mesentery was mainly due to an accumulation of cells at the free edge, where the mesentery has been separated from the intestine at the time of evisceration.

In the following days (5-dpe) there was a significant growth in the size of the thickening that will form the intestinal rudiment (Figure 1D). This rudiment acquired an elongated oval or tear-shaped morphology, although in some cases or sections the growth could be rather irregular, where different sections of the same animal at different levels might show somewhat dissimilar morphologies. As early as this stage a small protrusion was also observed at the most distal tip of the growing rudiment. This outcropping eventually formed a smaller structure or appendix that was separated from the main mesenterial thickening by a constriction (see Figure 1E).

At 7-dpe the intestinal rudiment continued to increase in size and now had an area about 20 times larger than the 3-dpe rudiment (Figure 1E). At this stage the structure acquired a more rod-like structure, which can be seen in cross-sections as circular in shape. This rudiment sometimes showed numerous and deep folds 


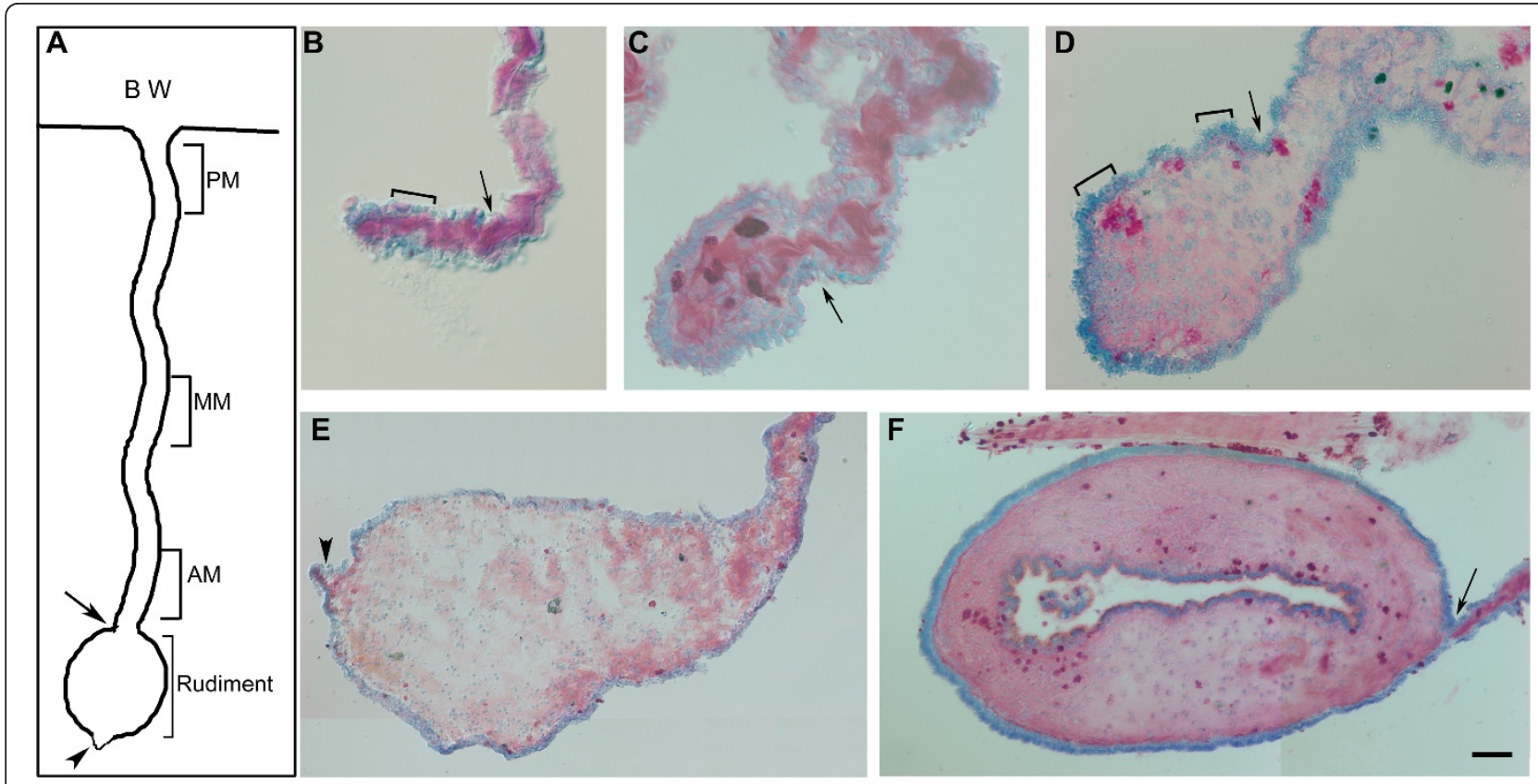

Figure 1 Stages of intestinal regeneration in H. glaberrima. (A) Diagram showing the relationship of the intestinal rudiment (brackets) to the mesentery and body wall (BW). The mesentery is divided into three sections: Proximal to the body wall (PM), medial mesentery (MM) and adjacent to the rudiment (AM). Transverse tissue sections of mesentery and regenerating intestine at (B) 1-, (C) 3-, (D) 5-, (E) 7- and (F) 10-days post evisceration (dpe) were stained with Toluidene Blue. (B) At 1-dpe the coelomic epithelium covers the tip of the mesentery but there is no clear thickening. (C) By 3-dpe, a small enlargement can be observed at the mesenterial tip. (D) By 5-dpe the intestinal rudiment has increased considerably in size and some areas of the mesothelium appear to have an increased number of cells (brackets) when compared to the 1-day mesentery (see brackets in Figure 1B). (E) By 7-dpe the rudiment has acquired a pear-shaped morphology and the appendix at the tip (arrowhead) is evident (F) At 10-dpe the lumen has formed and all tissue layers of the mature intestine can be found within the rudiment. Arrows signal the boundary between the forming intestinal rudiment and the mesentery. Bar = B-C $25 \mu \mathrm{m}, \mathrm{D} 50 \mu \mathrm{m}, \mathrm{E} \& \mathrm{~F} 100 \mu \mathrm{m}$

formed by the coelomic epithelium. The appendix that formed at the tip was also evident (Figure 1E).

In the 5-7-dpe animals, three distinct regions were easily distinguished in cross-sectioned profiles of the gut rudiment. The first was a long section of mesentery that extended from its attachment in the body wall to the intestinal rudiment. This mesentery, although undergoing some morphological changes (see below) maintained a similar morphology to that of the uneviscerated animal. The second compartment was the intestinal rudiment that formed at the tip of the mesentery. This rudiment was separated from the rest of the mesentery by a constriction that became more evident as the thickening increased in size. The third compartment was the appendix that had grown at the very tip of the mesentery. This was much smaller than the intestinal rudiment, and appeared to be mainly composed of coelomic epithelial cells.

In the 10-dpe animals, the rudiment continued to grow in size and acquired a cylindrical shape (Figure $1 F)$. In some animals a lumen formed. The luminal area comprised about 1/5 of the total cross-section area of the intestinal rudiment. Thus, the rudiment connective tissue and mesothelium continued to increase in size beyond merely an increase due to the formation of the lumen which itself caused a widening of the rudiment.

In summary, the first 10 days of regeneration were characterized by the formation of a tubular structure at the free end of the mesentery. Once formed this structure Meso-1 at about day 5, showing a 25 -fold increase in size between 3 and 10 days of regeneration (Figure 2).

\section{A novel monoclonal antibody labels the intestinal and mesenteric mesothelium}

One of the strategies used to dissect out the formation of the intestinal rudiment is to focus on particular cell populations involved in the regeneration process. Here we used a novel monoclonal antibody (Meso-1) that labels both major cell types of the gut mesothelium: the peritoneocytes, or coelomic epithelial cells, and the myocytes, or muscle cells, and follow the changes in this cell population during the first 10 days of regeneration.

In the normal non-eviscerated animals, the antibody labeled the mesothelium of the intestine and mesenteries (Figure 3A). The label appeared to be distributed homogenously in the cytoplasm and, in the myocytes, it was particularly strong around the muscle contractile 


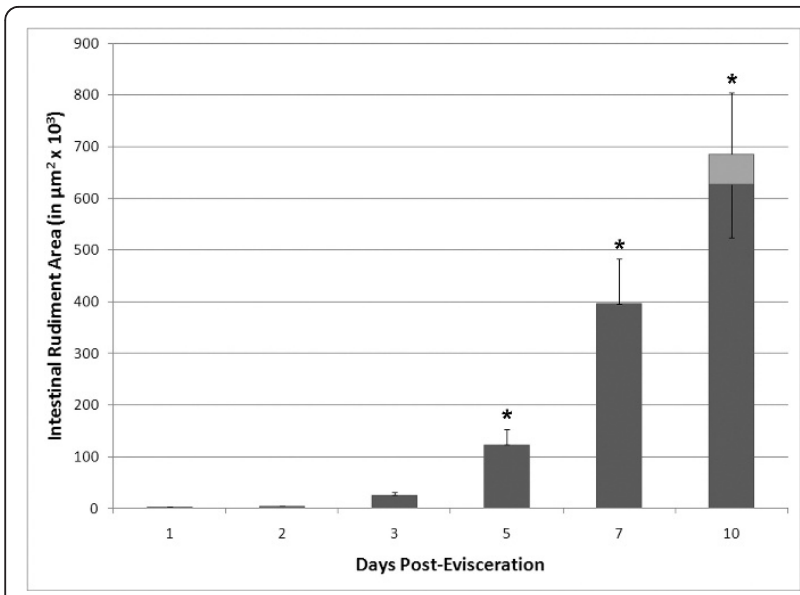

Figure 2 Quantification of the area of the intestinal rudiment during the process of intestinal regeneration. The area encompassed by the thickening of the mesentery was measured in transverse sections. The main growth of the structure begins 3 days after eviscerations. At 10 days a lumen has formed in all animals, thus the black bar at 10 days denotes only the area of tissue (does not include the lumen area), while the gray bar represents the total area of the intestine (including the area encompassed by the lumen). Each point represents the mean percentage \pm S.E. of at least 3 animals. ${ }^{*} p<0.05$.

apparatus, but did not label the muscle filaments themselves (Figure 3B-D).

\section{Mesothelial cells ingress during intestinal rudiment formation \\ Rudiment}

During the growth of the intestinal rudiment, Meso-1 labeling showed that cells within the mesothelium also underwent a transition, particularly those in the area at or close to the injury site (Figure 4A-E). First, in the early stages of regeneration (1-3-dpe) the cells within the rudiment became cuboidal or rectangular and formed what appeared to be a single layer of coelomic epithelium (Figure 4A \&4B). Second, the muscle layer disappeared from the growing found along the mesentery up to its tip (Figure 4A). More importantly, at 3dpe, some of the epithelial cells began to ingress into the connective tissue at the tip of the mesentery (Figure 4B). The ingression was evident in animals at 5-dpe (Figure 4C-E). Labeling with Meso-1 showed that the ingressing cells retained the mesothelial labeling as they transitioned from the epithelial to a mesenchymal morphology. The ingression process continued during the next few days and appeared to peak at 5-dpe (Figure 4FG). It is important to note that at this stage (5-dpe) some areas in the rudiment epithelium appeared to be several cells deep (see Figure 1D and $4 \mathrm{H}$ ), contrasting from the usual one-cell coelomic epithelium found in normal mesentery (see Figure $1 \mathrm{~B}$ and Figure 4A).
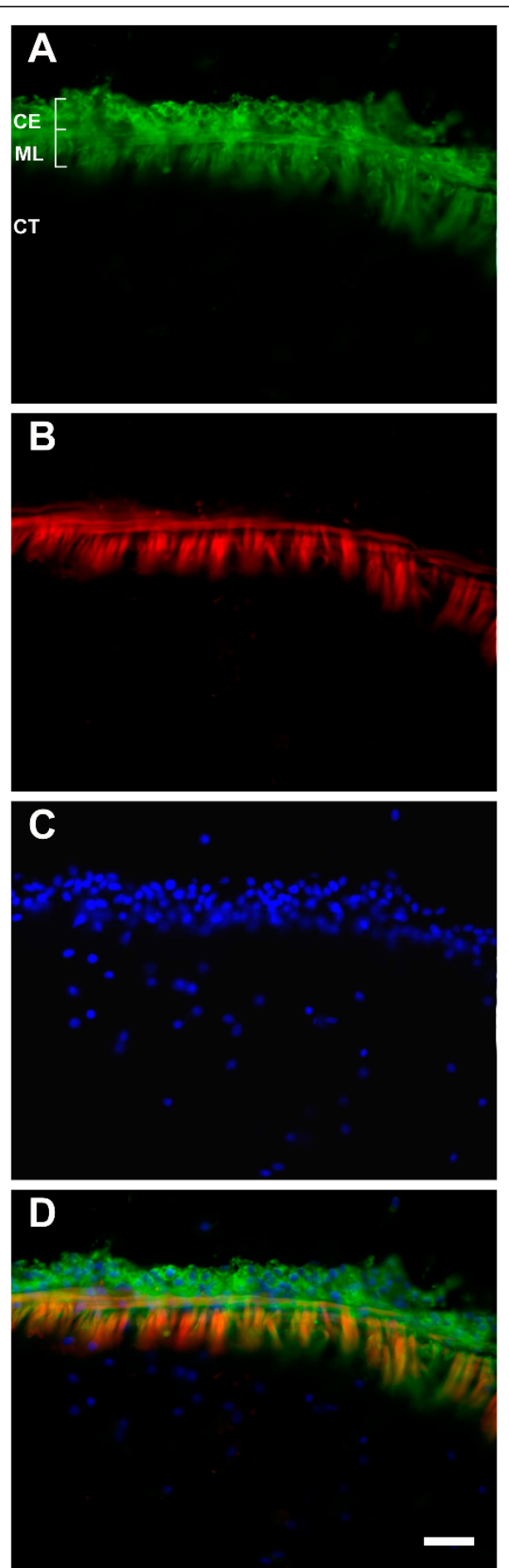

Figure 3 Longitudinal sections of normal uneviscerated large intestine, showing Meso-1 immunoreactivity. (A) Meso-1 labels the cells of the coelomic epithelium (CE) and the muscle layer (ML) (green). Cells of the connective tissue (CT) are not labeled. (B) The same section stained with rhodamine-labelled phalloidin only labels the muscle layer. (C) DAPI-labeled nuclei. (D) The colored overlay of the triple labeled section clearly shows that the Meso-1 antibody labels both mesothelium components while the phalloidin labeling is restricted to the muscle tissue. $\mathrm{Bar}=25 \mu \mathrm{m}$. 


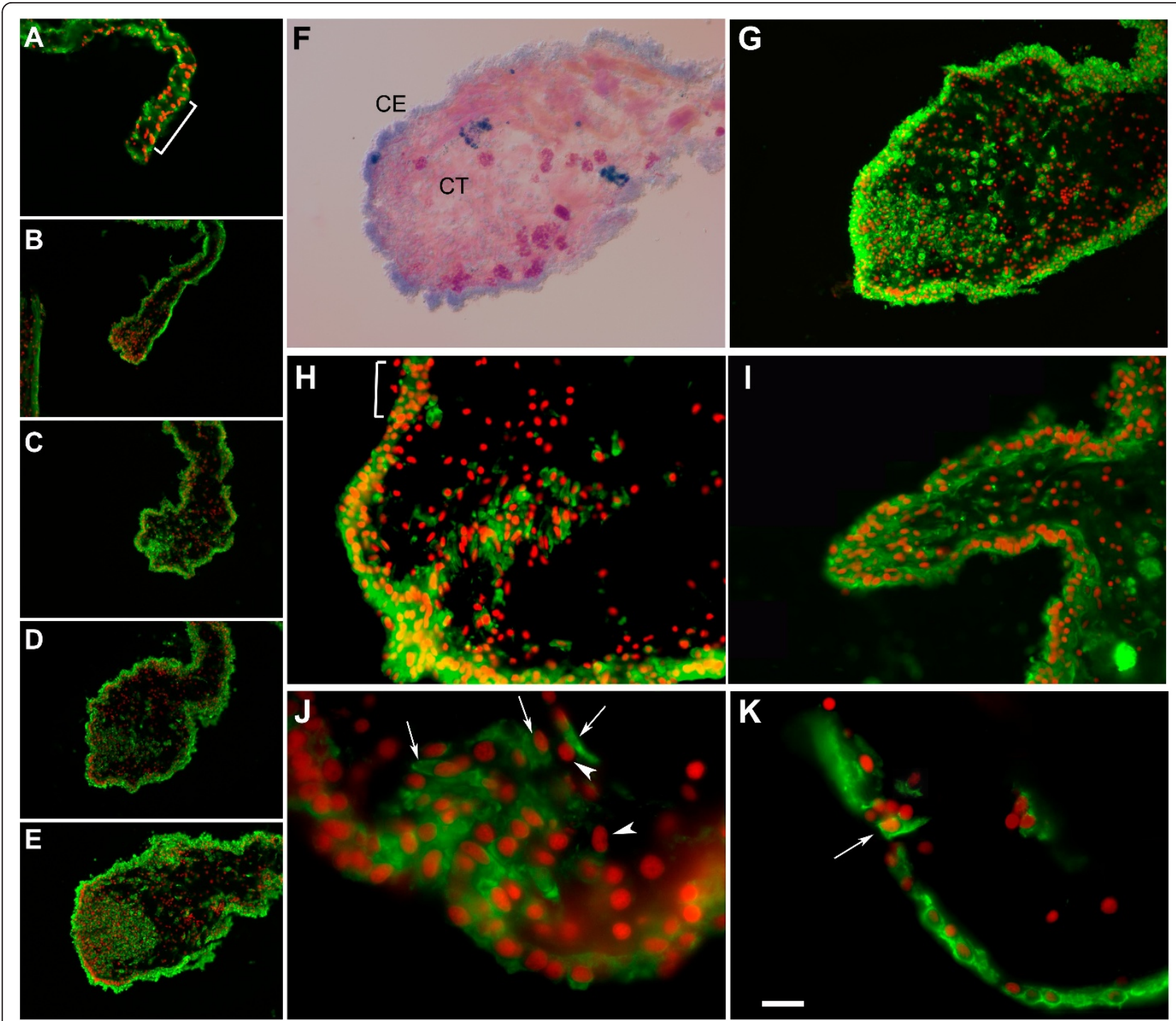

Figure 4 Meso-1 labeling of the regenerating intestine (Days 1-5 of regeneration). Meso-1 labeling (green) and nuclei DAPI stain (red) show the process of ingression and the concomitant changes in the rudiment during regeneration. (A-E) The mass of cells at the distal tip of the rudiment is not observed at 1-dpe (A), becomes noticeable at 3-dpe (B) and increases in the subsequent days (C-E). Transverse sections of (F) Toluidene blue staining of 5-dpe intestine, shows the thickening of the mesenterial tip that forms the intestinal rudiment and differential staining of the coelomic epithelium (CE) and connective tissue (CT) compartments. (G) A similar section labeled with Meso-1 antibody highlights the ingressing cells. (H-I) Two additional examples of ingressing cells at 5-dpe, one is an invagination of the coelomic epithelium (H) while in the other, cells can be observed moving from the rudiment tip into the connective tissue (I). Figure $\mathrm{H}$ shows regions in the coelomic epithelia (bracket) that are thicker when compared to those in the 1-dpe mesentery (see bracket in Figure 4A). At higher magnification (J) some Meso-1 labeled ingressing cells show an elongated nuclei and cellular morphology (arrows) while other cells within the connective tissue are not labeled (arrowhead). (K) At the lateral side of the rudiment, an isolated ingressing cell (arrow) can be observed. Bar $=(\mathrm{A}) 70 \mu \mathrm{m}(\mathrm{B}-\mathrm{E}) 100 \mu \mathrm{m}$ (F-G) $65 \mu \mathrm{m}$, (H-I) $30 \mu \mathrm{m}(J) 13 \mu \mathrm{m}$ (K) $20 \mu \mathrm{m}$. All sections are from 5dpe animals except A (1dpe) and B (3-dpe).

The ingressing cells formed a mass of cells adjacent to the tip of the mesenterial thickening. However, some labeled cells were also observed at a distance of up to $300 \mu \mathrm{m}$ from this cell cluster. The ingression site was usually associated with an invagination of the coelomic epithelium from which cells migrated into the surrounding connective tissue (Figure 4H \&4J). However, not all ingression sites were equal (Figure 4I) and sometimes the ingressing cells were clearly observed to be entering directly from the overlying epithelium (Figure 4K). Many of the ingressing cells were elongated and appeared smaller than those of the coelomic epithelium. Their nuclei were somewhat different in shape; while most cells in the connective tissue or coelomic epithelia had round distinctive nuclei, some cells at the tip had an oval nuclei. Initially, this ingression appeared to take 
place only at the free margin of the mesentery adjacent to the area where the appendix-like structure had formed. However, at later stages, the ingression of cells that began at the mesenterial tip was observed to take place within the lateral areas of the rudiment and even within the adjacent mesentery (although not at the large numbers observed at the tip) (Figure $4 \mathrm{~K}$ ).

Labeling with anti-collagen showed that the area where the ingressing cells (Figure 5A-B) were present was the area devoid of collagen (Figure $5 \mathrm{~A} \& 5 \mathrm{C}$ ), suggesting that the ingressing cells were associated with the previously documented process of ECM remodeling [9] or that the accumulating mesenchymal cells created a collagen-free region. Thus, the intestinal rudiment in the 5-dpe animals was divided into three distinct areas: the distal margin of the mesentery, where the injury occurred, containing a mass of ingressing cells, the middle area with a smaller number of mesenchymal cells and no collagen bundles, and, next to the mesentery, an area with fewer cells but with some remaining collagen fibers. There was a very clear boundary between the area occupied by collagen fibers and the area devoid of them, and cells apparently involved in phagocytosis of ECM components could be observed (not shown).

At 7-dpe, the number of ingressing cells seemed to have diminished but could still be observed at the distal end of the rudiment (Figure 6A). Immunolabeled cells were observed in many areas of the connective tissue within the mesenterial thickening (Figure 6B). These cells were rather large and showed a prominent nucleus, abundant cytoplasm and some small extensions. The number of these cells was greater close to the ingressing cells at the tip, suggesting that these ingressing cells were giving rise to the large cells that could be found within the intestinal rudiment connective tissue.

At this stage a single layer of myoepithelial cells could be found within the coelomic epithelia (not shown).
These cells originated from the overlying coelomic epithelia and were initially oriented in a circular manner but later provided the precursors of what will become the intestinal muscle layers [23].

At 10-dpe, the mesothelium of the rudiment remained strongly immunoreactive to Meso-1 and the forming muscle layer could be clearly observed (Figure 6C). At this stage, although some ingressing cells could still be observed, their number had greatly diminished. However, some of the immunolabeled large cells within the connective tissue appeared to be migrating toward the forming lumen and in some cases could be seen lying close to the basal end of the luminal cells (Figure 6D).

To quantify the ingression process we counted the number of cells within three areas of the rudiment connective tissue. These areas were: the tip (distal) area where the ingressing cell mass was found, the mid-section area where some Meso-1 labeled cells could be seen, and the proximal area to the mesentery where few if any Meso-1 labeled cells were found in the connective tissue (Figure 7). Results showed that at 3-, 5-, and 7dpe the cell density within the mass of ingressing cells was much higher than in other areas. Moreover, in the 5 -dpe stage there was also a larger density of cells in the mid section when compared to the area proximal to the mesentery suggesting that cells were indeed moving from the ingressing mass into the rudiment's connective tissue.

\section{Mesentery}

Meso-1 also revealed striking changes in the mesothelium of the mesentery that did not become part of the intestinal rudiment. These changes were characterized by a disorganization of the muscle and overlying coelomic epithelium (Figure 8). During regeneration, the muscle fibers present in the normal mesentery (Figure $8 \mathrm{~A} \& 8 \mathrm{C}$ ) disappeared and the mesothelium became almost a single layer of coelomic epithelial cells (Figure
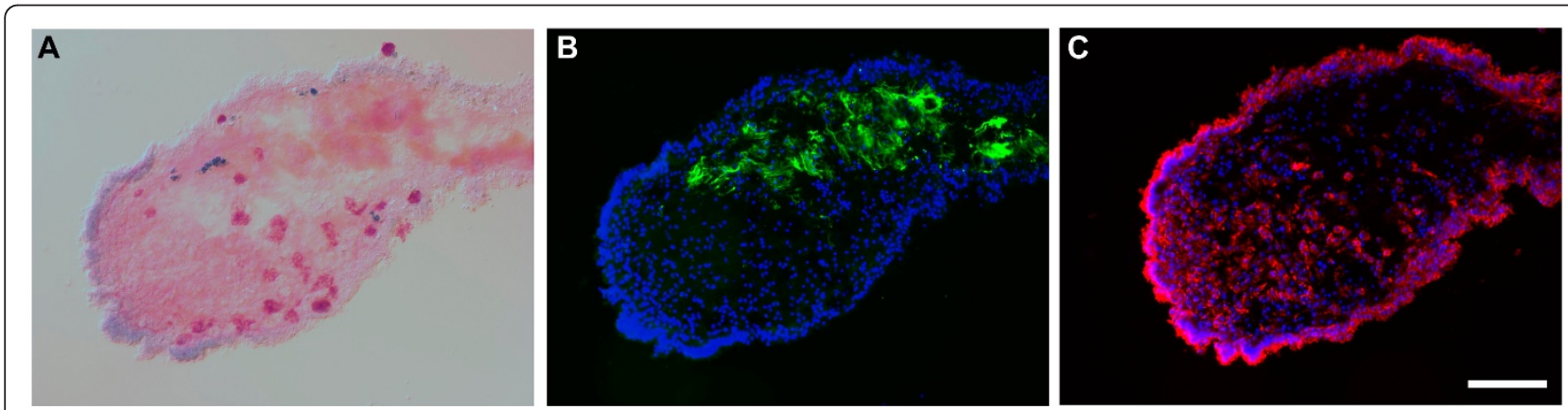

Figure 5 Meso-1 and collagen immunoreactivity during intestinal regeneration. Longitudinal sections of the 5 day regenerating intestinal rudiment showing (A) Toluidene blue staining (B) collagen immunoreactivity (green) and (C) Meso-1 labeling (red). Nuclei in B \& C are stained with DAPI (blue). A and B are the same section while $C$ is a similar section from the same animal. The figures clearly show that the area where the Meso-1 labeled cells are ingressing is devoid of collagen labeling, suggesting that the ingressing cells play a role in the remodeling of the extracellular matrix. Bar $=65 \mu \mathrm{m}$ 


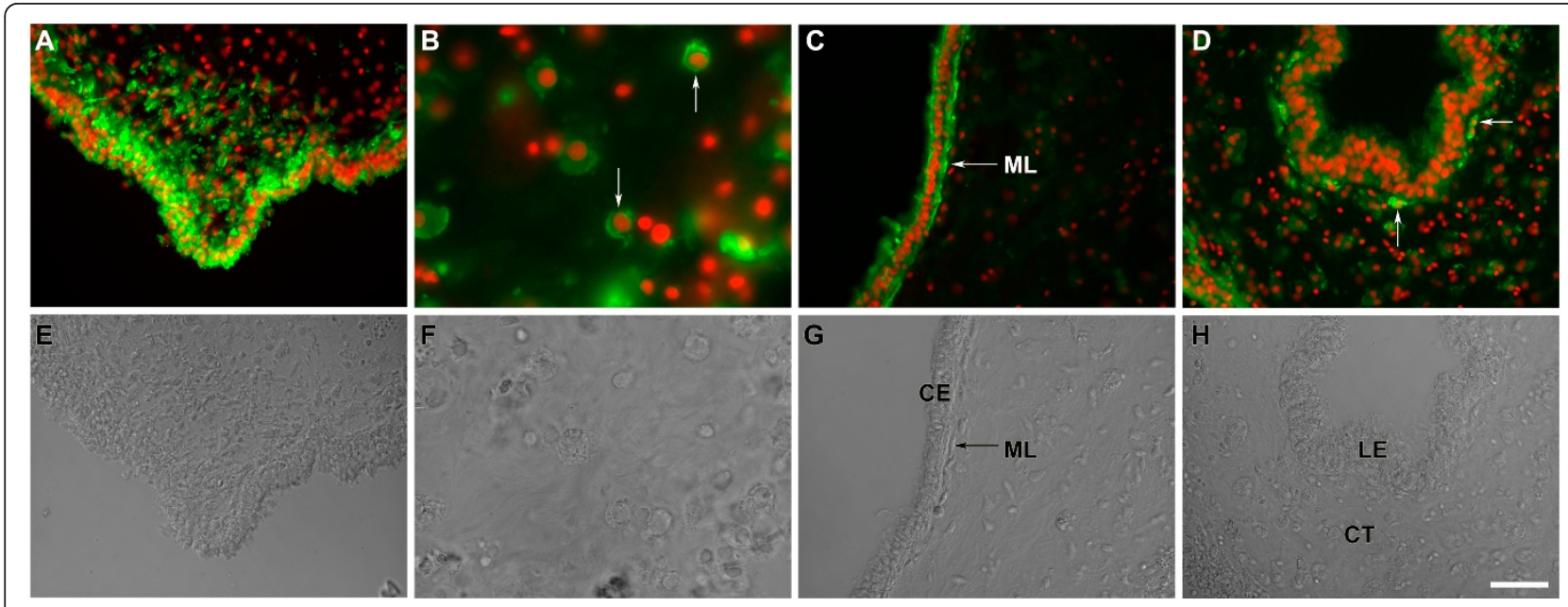

Figure 6 Meso-1 labeling of the regenerating intestine (Days 7-10 of regeneration). Meso-1 immunoreactivity (A-D) and phase microscopy $(\mathrm{E}-\mathrm{H})$ of 7 and 10 day regenerating intestine. In the 7-dpe Meso-1 labeling (A\&E) shows ingressing cells at the distal tip of the growing rudiment and (B\&F) some immunoreactive cells within the connective tissue (arrows). In the 10-dpe rudiment, as regeneration progresses, Meso-1 labels $(C \& G)$ the forming muscle layer $(\mathrm{ML})$ and $(\mathrm{D} \& H)$ cells that underlie the basal lamina of the luminal epithelium (LE). CE-coelomic epithelium, CTconnective tissue. Bar = All $50 \mu \mathrm{m}$ except B\& F $20 \mu \mathrm{m}$.

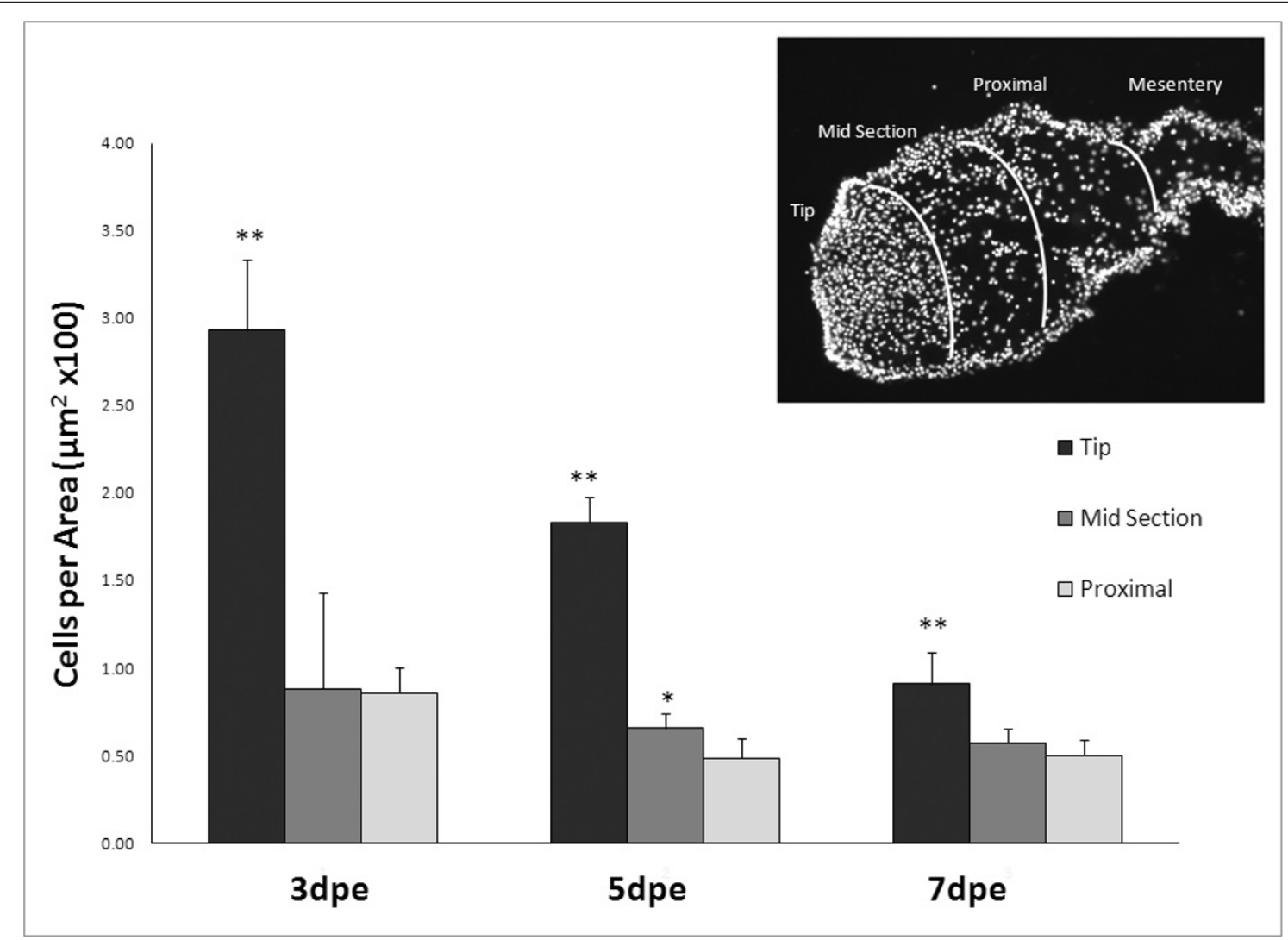

Figure 7 Quantification of cell density in the regenerating rudiment. The number of DAPI stained nuclei per $\mu \mathrm{m}^{2}$ was measured in tissue sections of regenerating rudiments of animals at 3-, 5-, and 7-days post evisceration. The connective tissue of the rudiment was subdivided into 3 different parts (tip, midsection and proximal). Insert shows an example of a rudiment with the areas that were measured. Each point represents the mean \pm S.E. of at least three animals. Statistical analyses were done by comparing the density of cells in the proximal section to those on other areas of the rudiment at the same stage. Different from proximal ${ }^{*} p<0.05,{ }^{* *} p<0.01$. 

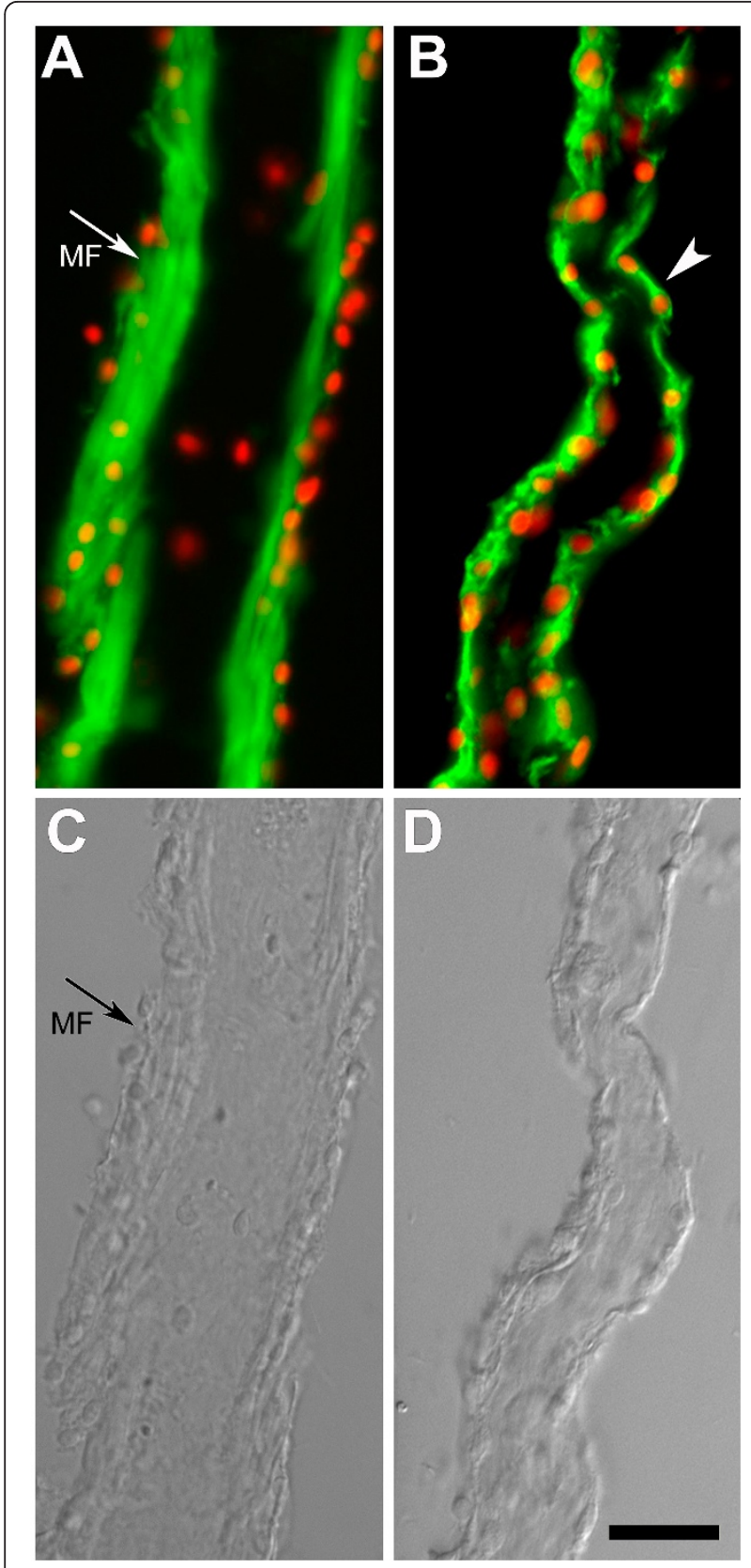

Figure 8 Mesothelial changes in the mesentery during intestinal regeneration. $(A-C)$ Meso-1 labeling of the mesentery of normal uneviscerated animals shows a well-organized muscle layer with muscle fibers (MF) cut longitudinally and a weakly labeled overlying coelomic epithelium. (B\&D) This organization is lost in the mesentery of 7-day regenerating animals where muscle fibers have disappeared and the mesothelium is mainly a one-cell layer (see cell labeled with arrowhead). Bar $=25 \mu \mathrm{m}$.

8B\&8D). In addition, some cells from the mesothelium appeared to move toward the connective tissue layer in a manner reminiscent of what was observed in the growing rudiment (not shown). However, these cells moved as individual cells and not as a cluster as observed in the rudiment tip. The changes in tissue organization and cellular morphology observed in the mesentery were more pronounced the closer one got to the growing rudiment and to a lesser extent (if at all) close to the body wall. They also followed a temporal gradient, where the disorganization and disappearance of muscle was observed close to the rudiment at 3-dpe, but were not observed in other areas of the mesentery until 5- or 7-dpe, always in a gradient where changes were more pronounced the closer one moved to the rudiment and less obvious the closer one moved toward the body wall. Minimal (if any) changes were observed in the area of the mesentery attached to the body wall, where muscle fibers remained clearly visible and little disorganization was observed up to 10-dpe.

In summary, we have observed that following evisceration, mesothelial cells close to the tip of the mesentery undergo a dramatic change, from an epithelium/myocyte layer to a coelomic epithelium rather different from the peritoneocyte epithelium found in normal non-regenerating mesentery. More importantly, some of the coelomic epithelial cells at the tip of the mesentery ingress into the connective tissue. Ingressing cells acquire a mesenchymal phenotype and are mainly present in the area of the rudiment that is devoid of collagen. The ingression process begins at 3-dpe, peaks at 5-dpe, continues at 7-dpe and decreases at 10-dpe.

\section{Cell proliferation is minimal during early stages of regeneration}

Previous studies from our laboratory showed low levels of cell division in the regenerating structure at 4-dpe; the earliest stage then studied [7]. To determine the contribution of cell proliferation to the thickening of the mesenterial tip and the formation of the intestinal rudiment, we studied the incorporation of BrdU in the Sphase of the mitotic cycle during the first 10 days of regeneration (Figure 9). A summary of the cell proliferation events in the regenerating rudiment can be observed in Figure 9C.

\section{Rudiment}

BrdU labeling showed low levels of proliferation at 1and 2-dpe, $(3.3 \pm 1.0 \%$ and $1.6 \pm 0.6 \%$ respectively) (Figure $9 \mathrm{~A})$. At 3-dpe, even though the thickening of the mesentery had begun, the percentage of dividing cells remained low and only $2.8 \pm 0.7 \%$ of the cells incorporated BrdU.

At 5-dpe, the number of BrdU labeled cells increased in all areas of the intestinal rudiment, correlating with an increase in its size (Figure 9B). In the connective tissue area, $10.5 \pm 2.7 \%$ of the cells now showed BrdU staining while in the epithelium $15.8 \pm 2.9 \%$ of the cells showed BrdU incorporation. Although labeled cells were found throughout the rudiment coelomic epithelium, 

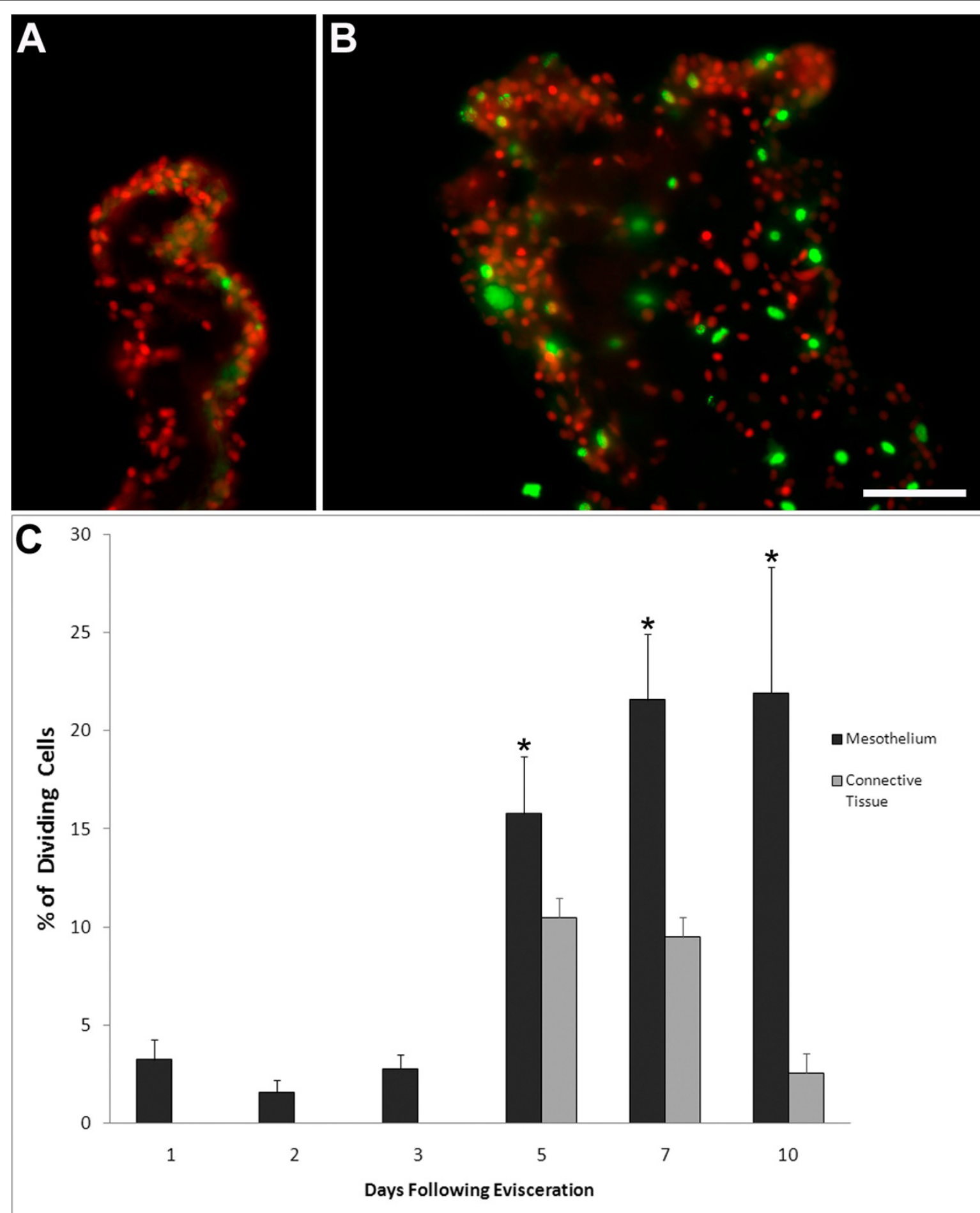

Figure 9 Patterns of cell proliferation in regenerating intestinal rudiments. Sections were labeled with an antibody against BrdU (green) and DAPI (red) to determine cell proliferation in the intestinal rudiment at (A) 2-dpe and (B) 5-dpe. Actively dividing cells were mainly observed in the coelomic epithelia of the rudiment of the 5-dpe animal with only one cell being labeled in the rudiment of the 2-dpe specimen. Bar= 50 $\mu \mathrm{m}$. (C) The percentage of BrdU-labeled cells or proliferation index was measured in the mesothelium (black) and connective tissue (gray) compartments of the regenerating intestinal rudiment. Each point represents the mean \pm S.E. of at least three animals. ${ }^{*} p<0.05,{ }^{* *} p<0.01$. 
their distribution was somewhat heterogeneous with more labeled cells found in the distal mesenterial area (the area of the regenerating rudiment at the opposite end of the mesentery which corresponds to the tip of the regenerating rudiment). However, there were no particular differences in cell proliferation either on the protrusion at the tip or among those that were ingressing.

At 7-dpe, cell division continued to increase in the coelomic epithelium $(21.6 \pm 3.4 \%$ of cells in this layer incorporated BrdU). Dividing cells were now more evenly distributed along all areas of the regenerating rudiment. In contrast, in the connective tissue layer, cell proliferation remained at levels similar to those of 5-dpe rudiments with $9.5 \pm 2.6 \%$ of the cells incorporating BrdU.

At 10-dpe, cellular proliferation in the coelomic epithelium remained high with $21.9 \pm 6.4 \%$ of the cells incorporating BrdU. In contrast, cell division in the connective tissue decreased to $2.9 \pm 0.3 \%$. At this stage, the luminal epithelium was present in the intestinal rudiment of only one of three specimens used for the BrdU experiments. The luminal epithelium of this specimen showed high cell proliferation with $59.8 \%$ of the cells incorporating BrdU.

\section{Mesentery}

Cellular proliferation patterns were also studied in two regions of the mesentery: the area adjacent to the regenerating rudiment and the medial mesentery localized half way between the free edge of the mesentery and its attachment to the body wall. Cell division was observed in the mesothelium and the underlying connective tissue.

In general terms the pattern of cell division resembles somewhat that of the intestinal rudiment. At 1 - to 3 dpe, around $1 \%$ of the mesothelial cells both in the mesentery adjacent to the rudiment or the medial mesentery showed BrdU staining. None of the cells in the connective tissue incorporated BrdU. A sudden change in the pattern of cell division was observed at 5dpe. Cell division in the mesothelial layer of the mesentery increased dramatically in both the adjacent and medial areas. In the medial area, $8.1 \pm 1.5 \%$ of the mesothelial cells showed BrdU labeling while a much higher percentage of cells were labeled in the adjacent area $(19.6 \pm 3.4 \%)$. In addition, cell division was first observed in the connective tissue layer of the mesentery, being higher in the medial area $(31.0 \pm 4.6 \%)$ than in the area adjacent to the rudiment $(15.2 \pm 3.1 \%)$.

At 7-dpe, the percentage of mesothelial cells labeled with BrdU in the area adjacent to the rudiment remained high $(19.7 \pm 4.5 \%)$. However, the percentage of dividing mesothelial cell in the medial segment had decreased to $2.8 \pm 1.4 \%$. In contrast, in the connective tissue layer, there were more labeled cells in the medial segment $(18.5 \pm 2.6 \%)$ than in the segment adjacent to the regenerating rudiment $(7.6 \pm 2.9 \%)$.

At 10-dpe, proliferation has decreased in the mesothelium of both adjacent $(1.3 \pm 0.9 \%)$ and medial $(1.5 \pm$ $1.1 \%)$ segments as well as in the connective tissue of adjacent $(1.5 \pm 1.4 \%)$ and medial $(1.0 \pm 0.8 \%)$ segments.

In summary, we have shown low levels of cell division in the regenerating intestine during the first 3 days of regeneration. Cell division increases at 5-dpe and is maintained up to 10 days in the mesothelium of the growing rudiment. The rate of cell division is always higher in the mesothelium than in the connective tissue layer.

\section{Mesenterial muscle de-differentiation begins during early stages of intestinal regeneration}

The low levels of cell division observed during the first few days of intestinal regeneration suggested that, at least initially, cells forming the regenerating structure were not originating from dividing precursors. What then is the origin of the cells that form the mesenterial thickening? Previous work from our laboratory had shown that regeneration was associated with dramatic changes in the remaining mesentery, particularly with dedifferentiation of the mesenterial muscle $[9,10]$. Thus, we studied, the timing and the relative number of dedifferentiating muscle cells in relation to the formation of the intestinal rudiment.

The process of muscle dedifferentiation is characterized by condensation of filaments into spindle-like structures (SLSs), which are then often eliminated into the extracellular space [24]. Although this phenomenon has already been documented in the mesentery during regeneration [10], the temporal and spatial profile of SLS formation has not been documented. Using rhodamine-labeled phalloidin to detect the SLSs, we found that muscle dedifferentiation began at the free end of the mesentery as early as $24 \mathrm{hrs}$ following evisceration (Figure 10A). Concomitant with the appearance of SLSs an increased disorganization and eventual disappearance of the muscle fibers was documented. Therefore, by the time the mesentery began to thicken and form the intestinal rudiment (3dpe), there were few if any SLSs or muscle fibers within the mesothelium next to the mesenterial tip. The level of dedifferentiation increased in the following days and peaked at 5-dpe within the area of the mesentery adjacent to the intestinal primordia (Figure $10 B \& 10 E)$. At this stage no muscle fibers were observed within this section of the mesentery. In the following stages, particularly at 7-and 10-dpe, as the number of SLS began to decrease, new muscle fibers were observed. 

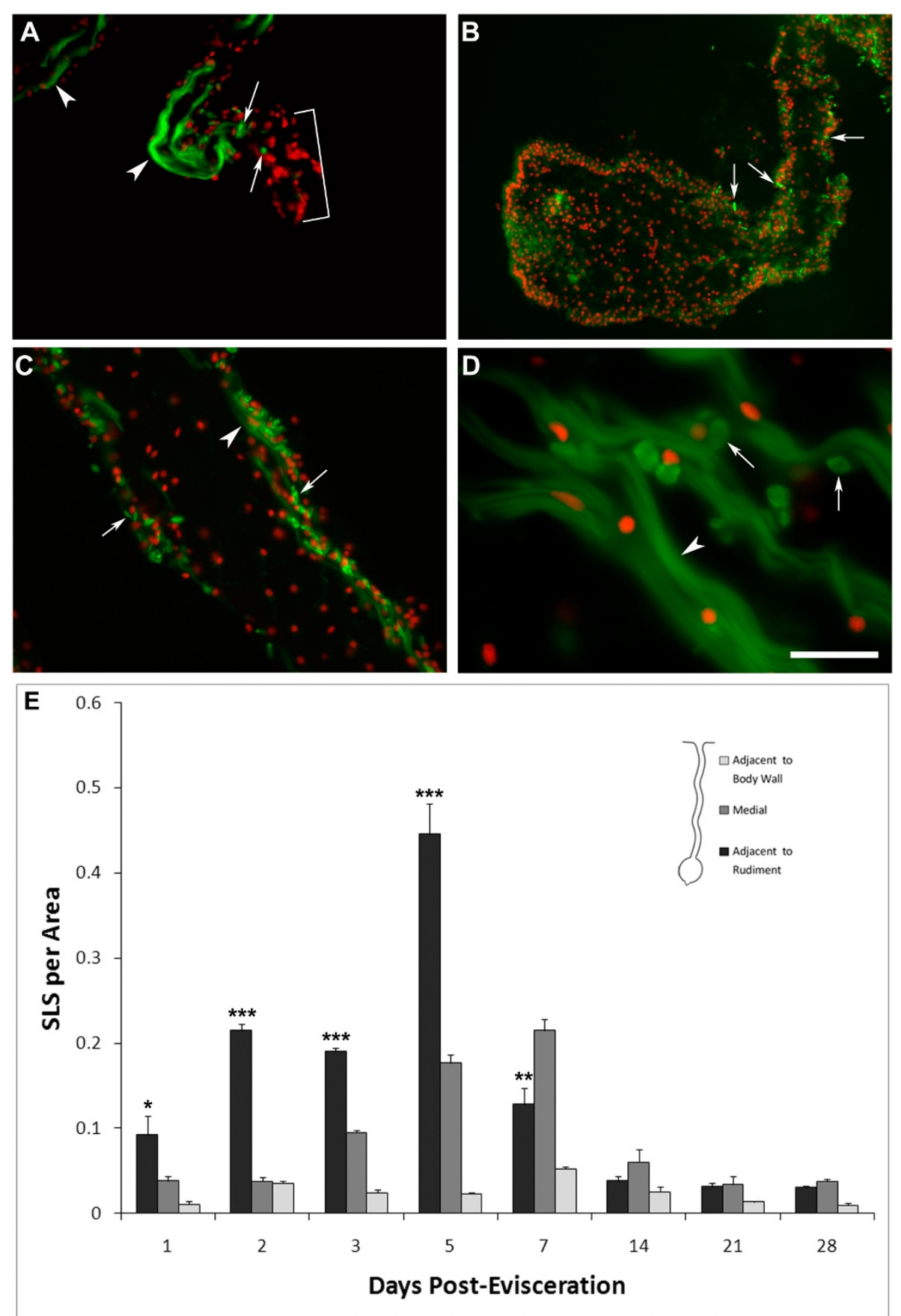

Figure 10 Formation of spindle-like structures (SLS) by muscle cells during intestinal regeneration. Double labeling of muscle fibers and SLS with rhodamine-labeled phalloidin (green) and cell nuclei with DAPI (red). (A) At 1-dpe, muscle fibers have disappeared from the tip of the mesentery (brackets) and SLS (arrows) are found close to the remaining muscle fibers (arrowheads). (B) At 5-dpe, the intestinal rudiment and adjacent mesentery are devoid of muscle fibers but some SLS (arrows) are present. (C) At 7-dpe, the area of the mid mesentery has SLS (arrows) and a few remaining muscle fibers (arrowheads), while (D) the mesentery close to the body wall has abundant muscle fibers (arrowheads) and only a few SLS (arrows). Bar = (A\&C) $65 \mu \mathrm{m}$, (B) $125 \mu \mathrm{m}$, (D) $25 \mu \mathrm{m}$. (E) The number of SLS was measured in different areas (corresponding to $\sim 40,000 \mathrm{um}^{2}$ ) of the intestinal rudiment and mesentery in regenerating animals from 1 to 28 -dpe. In the mesentery adjacent to the rudiment, SLS show an increase from 1-dpe, peaking at 5-dpe. Areas of the mesentery distant to the regenerating structure (medial and distal) show a smaller amount of SLS and a peak at later stages. Each point represents the mean \pm S.E. of at least three animals. ANOVA analysis showed significant differences in the mesentery adjacent to the rudiment. Asterisk show the results of t-test comparisons of different stages to dpe-28 ${ }^{*} \mathrm{p}$ $<0.05 .{ }^{* *} p<0.01$. ${ }^{* * *} p<0.001$. 
Similar dedifferentiation processes were observed in other sections of the mesentery but fewer in number and at later stages (Figure 10C-E). In the mesentery adjacent to the intestinal rudiment, SLS formation started increasing at $24 \mathrm{hrs}$ following evisceration and a peak was observed at 5-dpe, with a gradual decrease in the number of SLS thereafter. In the medial mesentery SLS formation began to increase (Figure 10C) and peaked slightly later. Similarly, disorganized muscle fibers and SLSs were also found in the section of the mesentery adjacent to the body wall (Figure 10D), but the number of SLS was much smaller and there was never a complete disappearance of the muscle fibers. SLS quantification showed that, in the mesentery adjacent to the rudiment, a peak of 150 SLSs per field of view was observed at $5 \mathrm{dpe}$, the peak in the medial mesentery was 70 (at 5-7 dpe) and in the mesentery close to the body wall it was 30 (at 7-dpe) (Figure 10E).

In summary, we have shown that muscle dedifferentiation begins very early during regeneration and occurs in a temporal and spatial gradient beginning at the free end of the mesentery soon after evisceration and moving toward the body wall in subsequent days.

\section{Discussion}

We have now studied various cellular events that take place during the initial stages of intestinal regeneration in H. glaberrima. The results show that formation of the early intestinal regenerate occurs by the thickening of the mesenterial tip and that the initial steps in this process occur with little contribution from cell proliferation. On the other hand, concurrent with this process there are significant increases in muscle dedifferentiation adjacent to the regenerating structure. Finally, a previously undescribed mechanism by which coelomic epithelial cells ingress to form the mesenchyme at the tip of the regenerating structure is shown. Here we discuss the intestinal regenerative process in relation to what is known of regenerative processes in other echinoderms.

Our findings can be integrated into a working model of the cellular processes that form the intestinal rudiment. The initial event, is the healing of the wound by re-epithelialization. Contemporaneous with wound healing, the two cellular phenotypes within the mesothelium, myocytes and peritoneocytes, in the mesentery adjacent to the wounded edge, begin a process of dedifferentiation. The process is clearly observed in the myocytes due to the formation and elimination of SLSs, however, in other holothurian species, there is evidence that peritoneocytes also dedifferentiate, as determined by the loss of intermediate filaments [25]. Some of the dedifferentiated cells remain within the mesothelium and will give rise to the coelomic epithelium that surrounds the intestinal rudiment. As time proceeds, dedifferentiation continues in a retrograde gradient from the tip of the regenerating mesentery towards the body wall. The growing number of dedifferentiated cells provides the source for the coelomic epithelium to move as a sheet toward the tip of the mesentery. At about 3 days of regeneration, the cells of the coelomic epithelium begin to ingress into the underlying connective tissue layer, transforming from epithelial to mesenchymal phenotype. This ingression increases in the following days forming a mass of cells at the tip of the mesentery. As cells ingress and disseminate within the enlarging rudiment, it begins to acquire the tear-shaped morphology that shows an enlargement close to the tip. Ingressing cells undertake the changes needed to prepare the growth of the new structure. Among these changes are the remodeling of the ECM [9] and the overall growth of the structure necessary for the migration of luminal cells [7] and the formation of the intestinal lumen.

\section{Cell dedifferentiation and proliferation}

The two cellular mechanisms that provide most of the cells for the regenerating intestinal rudiment, cell dedifferentiation and proliferation, appear to be shared by all regenerative events. They have been documented in regenerative processes not only in echinoderms but also in most animal groups.

\section{Cell dedifferentiation}

Cell dedifferentiation has been well described in echinoderms, where it has mostly been studied in muscle [12]. The regenerative processes where myocyte dedifferentiation is thought to be involved include muscle regeneration [24,26], cuvier tubule regeneration [27], and limb regeneration in crinoids [28,29] and asteroids [30]. In vertebrates, cell de-differentiation was first described over 50 years ago [31] and recent experiments have confirmed that it is indeed an important process for regenerating structures. Dedifferentiation has been mainly studied in amphibians and fishes where it has been documented in various cell types including iris cells [32], dermal fibroblasts [33] and muscle cells [34]. Moreover, recent tracing technologies have shown that dedifferentiated cells are incorporated into the regenerated structure, although their differentiation potential might be more restricted than previously thought [35-37].

In the holothurian, though we can document extensive cell dedifferentiation (by the presence of the SLS) we cannot certify as to the final destiny of these cells. These cells retain the Meso- 1 label and some of them are probably incorporated into the coelomic epithelium. (It is important to remember that the echinoderm muscle cells are part of the mesothelium and thus lie over the same basal lamina as the epithelial cells). Recent 
experiments from our laboratory also suggest that dedifferentiating cells are not undergoing apoptosis. Although we have shown that during the first week of regeneration up to $5 \%$ of the mesothelial cells undergo apoptosis [21], most of the dying cells are observed in the area of the rudiment close to the mesentery, with very few apoptotic cells found within the mesentery. That the area covered by dedifferentiating cells is much more extensive than that where apoptosis is taking place suggest that there is no direct correlation between both processes. Therefore, although we propose that dedifferentiated muscle cells are actively participating in the regeneration process by becoming coelomic epithelial cells, at present, the technological limitations of our model system do not allow an in vivo study where the transformation and migration of live cells can be followed in real time to clearly determine the fate of the dedifferentiated cells.

\section{Cell division}

Cell proliferation has been a hallmark of the undifferentiated cells within the regenerating vertebrate blastema $[4,31,38]$. These cells, mainly found within the connective tissue underlying the epidermis proliferate, increasing their numbers, and eventually differentiate into the cells of the regenerated tissues. In contrast, in the holothurian intestinal system, cell proliferation takes place primarily in the coelomic epithelium. It begins slowly during the first week of regeneration, peaks during the second week of regeneration, and continues at lower levels for the following weeks [7]. We propose that cell division serves two purposes; first, it provides additional cells in the coelomic epithelium to counterbalance those that ingress. Second, it provides the cells necessary for the increase in area of the coelomic epithelium as the regenerating intestine expands and grows in size.

In this respect it is important to note that the proliferating coelomic epithelium will give rise not only to the peritoneocytes of the new intestine but also to the myocytes of the underlying circular and longitudinal muscle layers [12,23]. Immunohistochemical and ultrastructural studies done in various sea cucumber species suggest that these muscle cells originate from the dividing cells in the epithelium and differentiate as they move basally toward the basal membrane. However, in contrast to the ingressing cells they do not cross over the basal lamina [12]. In addition, the coelomic epithelium probably gives rise to the neurons within the mesothelium, but this differentiation has not been well studied.

It is important to highlight here some of the recent molecular data obtained in our laboratory [21]. The expression of two genes associated with inducing proliferation or inhibiting apoptosis, survivin and mortalin, is higher on the distal side of the rudiment, next to the injury site. However, what is really important is that the enhanced expression of both survivin and mortalin in the rudiment is indicative of a molecular transition in the mesothelial cells of the rudiment that goes hand in hand with the de-differentiation shown previously and with the increase in cell proliferation. Thus, the two genes serve as markers of the morphological and molecular changes that the mesothelium undergoes during regeneration. Even more interesting is the fact that initial expression of the both genes takes place in cells at the distal free margin of the mesentery corresponding to the cells that will undergo the EMT.

\section{Epithelial to mesenchymal transition (EMT)}

The main difference or peculiarity of the holothurian regenerative structure is the origin of the mesenchymal cells. The holothurians show a hitherto undescribed regeneration mechanism by which cells from the epithelial layer ingress into the connective tissue layer and become mesenchymal cells. This appears to occur primarily along the gut autotomy plane and where a constriction forming an appendix has developed. EMTs have been well documented in developing embryos of animal species [39]. In echinoderms, in particular, they are important in the formation of the mesenchymal cells during gastrulation. Moreover, in adult animals, EMT can play important roles in wound healing, and cancer progression [40].

This mechanism contrasts with other regenerative events, particularly arm regeneration in ophiuroids and asteroids, as well as limb or fin regeneration in vertebrates where no cellular migrations are observed between the overlying epithelium (epidermis) and the underlying tissues. Nonetheless, the origin of cells for the tissue or organ regenerate is highly variable among the various animal groups. For example, the planarian blastemas are formed by neoblasts that migrate to the injury site [2,3]. In fish, fin regeneration blastemas are formed by migrating proliferating mesenchymal cells $[41,42]$ while amphibian limb blastemas are formed by dedifferentiating cells in the injured limb $[4,5]$.

It is also important to consider what might be significant differences between many regeneration model systems, such as limb regeneration and visceral regeneration. During limb regeneration the blastema is formed under the epidermis. This epithelial layer provides structural support and protection against loss of fluids and attack by pathogens. Ingression of epidermal cells into the connective tissue underneath, to occur, would bring with them pathogens that might be present in the external milieu. Visceral regeneration, on the other hand, occurs within the coelomic cavity, a compartment that (in our model system 3 days following evisceration) should be pathogen-free. Thus, the 
ingression of cells from the overlying epithelium should carry no risk to the regenerating rudiment. It is interesting, in this respect that reports of body wall muscle regeneration [24] and Cuvier tubule regeneration in holothurians [27] are also associated with a migration of cells from the overlying epithelium into the underlying tissues, albeit, to a lesser extent than the ingression observed during intestinal regeneration, since in these cases the cells do not cross the basal lamina. Two other cases in the echinoderm regeneration literature hint at ingression of mesothelial cells. The first is the formation of the anterior gut in sea cucumbers of the family Dendrochirota where the mesothelial cells have been postulated to give rise to the luminal epithelium [25]. Second is the regeneration of the digestive system in the crinoid Antedon mediterranea [43]. In this species, cells from the coelomic epithelium also appear to enter the underlying connective tissue and give rise to mesenchymal cells. The authors have also proposed that the entering cells eventually trans-differentiate into luminal epithelial cells thus reversing from an EMT to a mesenchymalepithelial transition.

EMT during vertebrate visceral regeneration has also been shown. Zebrafish can regenerate their hearts following removal of up to $20 \%$ of the ventricular myocardium [44]. In this model system, epicardial cells undergo EMT, invading the wound and generating endothelial and smooth muscle cells of the vasculature [45]. Thus, the available data suggests that in both vertebrates and invertebrates EMT events could be playing major roles in visceral regeneration.

\section{What is the role of the ingressing cells?}

Although at present it is difficult to clearly establish the role of the ingressing cells in the sea cucumber, our understanding of the ongoing cellular events do provide some possible explanations. First, they are probably involved in the remodeling of the ECM that occurs in the regenerating structure. Ingressing cells, might give rise to the phagocytic amebocytes found 3-5 days after evisceration that are responsible for the degradation of the extracellular matrix, particularly of the collagen component $[9,10]$. Moreover, there is a temporal and spatial correlation where ECM remodeling occurs at the same time that cells are ingressing and the area in the intestinal rudiment where the ingressing cells are found is the area that is devoid of collagen. Ingressing cells might have other roles, among these the formation of the new ECM, being the precursor to new cells in the regenerating mesenchyme or even participating in the formation of the intestinal lumen. In the latter, it is important to highlight that some of the ingressing cells appear to contact the luminal cells in the 10dpe animals and that this interaction might be essential for the formation of the luminal basal lamina and the maintenance of the luminal epithelial layer.

On the other hand, it is important to emphasize that ingressing cells in the holothurian are not necessarily equivalent to the "blastemal cells" found in regenerating amphibian limbs [4] or fish fin blastemas [42,46] nor to planarian neoblasts [47]. The main difference, other than their origin, is shown by the limited proliferation activity; there is less BrdU incorporation in these cells and proliferative events last less than in cells of the overlying coelomic epithelium, or the forming luminal epithelium. Thus, once again it seems that the mesothelial cells are the key players in providing cells for the regenerative structure.

\section{Regeneration in echinoderms}

Echinoderm regeneration studies have mainly focused on arm regeneration in crinoids [48], ophiuroids [49,50] and sea stars $[30,51]$ and in muscle and visceral regeneration in holothurians $[12,24,52]$. However, instead of showing similar processes involved in the regeneration of different structures or organs, these studies have focused on the differences among the echinoderm groups. Take for example the studies by Candia Carnevalli's group that showed that the regenerating arm of the crinoid $A$. mediterranea is mainly formed by undifferentiated proliferating (BrdU-incorporation) mesenchymal cells underlying the epidermis [28,29]. In contrast, the cells that give rise to the regenerated arm in two sea star species; Leptasterias hexactis [51] and in Asterias rubens [30] appear to originate from dividing cells in tissues of the arm stump that migrate into the injury area.

The differences in regeneration processes among the echinoderms might be due to factors that have to do with availability of cell precursors, such as the number of cell precursors or the distance where they can be found or produced in relation to the injury. The echinoderm coelomic epithelium has been considered a tissue capable of giving origin to a large number of cell types, including myocytes, peritoneocytes, coelomocytes and possibly others $[12,53]$. Thus, during intestinal regeneration once the wound is healed (following the evisceration rupture) the mesentery tip that will give rise to the intestinal primordia is surrounded by cells capable of producing precursors to many cell phenotypes. It also needs to be taken into account that the number of cells available within the mesenterial connective tissue is very small and the nearest source of cells, other than the mesothelium, would be the body wall. In this case, cells would have to migrate a considerable distance via the mesentery toward the tip where intestinal regeneration takes place [54]. In this scenario, the cells of the mesothelium, are capable of providing most of the cells needed for intestinal regeneration. 
Therefore, what we propose is that echinoderm regeneration relies on both cell dedifferentiation and proliferation; in cases where large number of cells are needed to regenerate a body structure both events can be observed. Otherwise, in some cases where the dedifferentiating cells are nearby or small number of cells are needed, one of the two mechanisms can take place preferentially.

\section{Conclusions}

Our data show that three events are important in forming the intestinal rudiment during the process of intestinal regeneration. The initial event is the dedifferentiation of the mesenterial muscle layer that begins near the free-tip of the mesentery and spreads gradually toward the body wall. Second, is the ingression of cells at the tip of the mesentery providing some of the mesenchymal cells for the connective tissue. Third, is cellular proliferation. Cell division begins later during the regeneration process and mainly occurs within the mesothelium of the growing rudiment and mesentery. Two of these events, cell dedifferentiation and proliferation are common to many regenerative processes, both in vertebrates and in invertebrates. The observed epithelial to mesenchymal transition might be particular to the regeneration of visceral organs.

Our results provide a clearer view of the cellular events involved in the formation of the intestinal rudiment during visceral regeneration. They highlight the dedifferentiation, proliferation and epithelial-mesenchymal transition of mesothelial cells and their possible role as precursors of the new intestinal cells. Nonetheless, new questions emerge that need further investigation. Among these are the identification of the physical and molecular factors associated with the EMT and dedifferentiation, as well as the possible role of the ingressing cells in the formation of the intestinal lumen.

\section{Methods}

\section{Animals}

Adult individuals of Holothuria glaberrima were collected from the northern coast of Puerto Rico. They were kept in seawater aquaria. Evisceration was induced chemically with intracoelomic injections of $\mathrm{KCl} 35 \mathrm{mM}$ (3-5 mls per animal). At least three animals were used for each experiment at stages 1-, 2-, 3-, 5-, 7-, and 10days post-evisceration (dpe).

\section{Antibody production}

Two mice were immunized with a cellular homogenate obtained by scraping the coelomic epithelium of 7-dpe regenerating longitudinal body wall muscles of $H$. glaberrima [55]. Fifty microliters of the emulsion (equal volumes of TiterMax (Sigma) and the extracted tissue solution) were injected intraperitoneally in each mouse. After thirty days, the serum was extracted and utilized as a polyclonal antibody source for immunohistochemistry.

One animal was boosted one week before spleen dissection and used for the production of monoclonal antibodies. The fusion was performed by the stirring method [8,56] with a spleen:myeloma (SP20) ratio of 6:1. The supernatant of wells exhibiting good hybridoma growth were used for immunohistochemical assays of holothuroid body wall. We selected the Meso-1 clone due to its labeling of the mesothelium of both the intestine and the body wall muscles.

\section{Immunohistochemistry}

Animals were anesthetized by keeping them in $0.5 \% 1$, 1, 1-Trichloro-2-methyl-2-propanol hydrate in seawater for 20-30 $\mathrm{min}$. The regenerating digestive tube was dissected out and fixed overnight in $4 \%$ paraformaldehyde, in $0.1 \mathrm{M}$ PBS, rinsed with the same buffer three times for $15 \mathrm{~min}$ and cryoprotected in $30 \%$ sucrose/PBS until sectioned. The cryosections $(20 \mu \mathrm{m})$ were obtained using a Leica CM1850 cryostat.

Immunohistochemical techniques have been described previously [8,57]. In brief, the primary antibody was left overnight and sections were placed in a humid chamber at room temperature. The next day, the slides were washed three times with $0.1 \mathrm{M}$ PBS for $15 \mathrm{~min}$. Secondary antibody was applied for an hour. Following three more PBS washes, slides were mounted in buffered glycerol containing DAPI and observed and analyzed using a Nikon Eclipse E600 fluorescent microscope. The antibodies used were Meso-1 and anti-collagen $\mathrm{HgCol}$ [9]. Those slides that were stained with polyclonal primary antibodies, were treated with $1 / 50$ goat serum prior to the application of the primary antibody to reduce nonspecific background fluorescence.

In some cases, immunofluorescence was performed in fixed sections as described and after incubation with the secondary antibody, slides were incubated for one minute in toluidene blue. Slides were washed two additional times with PBS, 15 min each before mounting.

In other cases, muscle labeling was done using fluorescent-labeled phalloidin by adding it during the incubation with the secondary antibody. Phalloidin-FITC (Sigma P5282), or Phalloidin-TRITC (Sigma P1951) were used at final concentrations of $1: 1,000$ and 1:4,000 respectively.

Measurements of the rudiment area were done using ImageJ software (http://rsbweb.nih.gov/ij/). At least 3 sections were measured from each animal and at least 3 animals were used for each stage.

\section{Cell quantification}

Tissue sections from regenerating animals at 3-, 5- and 7 -dpe regeneration stages were immunolabeled with the 
Meso-1 antibody and DAPI. Using the Meso-1 labeling the area of the connective tissue of the rudiment was subdivided into 3 parts: the distal area where the ingressing cell mass was present and most, if not all, cells were Meso-1 labeled, the midsection area where large, individual Meso-1 labeled cells were found together with unlabeled cells, and the proximal area, adjacent to the mesentery where most of the cells were not labeled with Meso-1. The area of each sub-division was measured using ImageJ software (http://rsbweb.nih.gov/ij/) and the number of DAPI stained nuclei counted. The number of DAPI nuclei divided by the subdivision area was used to determine the cell density in each area. The cell density for each area was compared to other areas of the same stage using t-test.

\section{Cell division}

Regenerating animals at various regeneration stages (1-, 2-, 3-, 5-, 7-, and 10-dpe), were injected with BrdU (SIGMA, Cat. \#B5002) at a concentration of $0.5 \mathrm{mg} / 100$ $\mu \mathrm{L}$ per $\mathrm{kg}$ (animal wet $\mathrm{wt}$ ). Animals were kept in an aquarium and sacrificed 4 hrs after the injection.

The immunohistochemistry protocol described above was followed with some additional steps that include: A wash with Triton $100 \mathrm{x}(0.2 \%)$ for 15 min prior to the application of the primary anti-BrdU antibody. Two washes with $0.1 \mathrm{M}$ PBS for $15 \mathrm{~min}$. A one-hour treatment with $0.05 \mathrm{M} \mathrm{HCl}$. Another PBS wash followed by treatment with the murine monoclonal anti-5-bromodeoxyuridine (GE Healthcare Code: RPN 202). The antibody was diluted 1:4 in RIA Buffer prior to use. Slides were mounted as described above.

BrdU immunoreactive cells were counted and the number was normalized relative to the total number of cells labeled with DAPI within the visual field using the 40x objective. The ratio of BrdU/DAPI labeled cells was compared between the different regenerating stages. At least four animals were used per stage and at least four sections were analyzed per animal.

\section{SLS quantification}

Myocyte dedifferentiation has been described in several echinoderm species $[12,24]$. A hallmark of muscle dedifferentiation is the formation of spindle-like structures (SLSs). These are cell-derived structures that contain portions of the contractile apparatus of the dedifferentiating cells. Thus, the number of SLSs found in a tissue correlate with the number of cells undergoing dedifferentiation. In order to determine the extent of muscle dedifferentiation in the regenerating intestine, the number of SLSs was quantified at each stage of regeneration.

SLSs were labeled using rhodamine-labelled phalloidin as described elsewhere [55]. To quantify the changes in SLS formation two methodologies were used. First, the number of SLS in a segment of mesentery measuring $\sim 40,000 \mathrm{um}^{2}$ was counted. This was done by using the $20 \mathrm{X}$ objective and measuring the tissue within the microscope field of view. Alternatively, the number of SLS and the mesentery area where they were present was measured to establish the SLS density. Both techniques provided similar results in terms of the pattern of SLSs present in different parts of the mesentery. The number of SLSs/per area were measured at three different levels of the mesentery; near the body wall, medial and near the regenerating rudiment. All areas used for measuring SLSs were of similar size $\left(\sim 40,000 \mathrm{um}^{2}\right)$. At least three animals were used for each stage and at least two sections from each animal were counted.

\section{Statistical Analyses}

Statistical analyses were done using t-test and ANOVA. All values are reported as mean \pm standard error.

\section{Acknowledgements}

This research was funded by NIH (1SC1GM084770) and NSF (IOS-0842870). The authors want to thank Dr. Vladimir Mashanov for spirited discussions and valuable comments on the manuscript. In addition, the authors would like to thank two anonymous reviewers for many helpful suggestions on how to improve the manuscript.

\section{Authors' contributions}

JGA conceived the study, participated in the interpretation of the results and wrote the manuscript. GVT carried out most of the immunohistochemical results with Meso-1 and obtained and analyzed the toluidene blue data. JF performed and analyzed the BrdU experiments. RR carried out the

experiments with collagen. ARC carried out the experiments and analyzed the data on SLSs. JESM produced the Meso-1 antibody. KT contributed to the interpretation of wound healing and rudiment formation. All authors read and approved the final manuscript.

Received: 23 May 2011 Accepted: 17 October 2011

Published: 17 October 2011

\section{References}

1. Sánchez-Alvarado A, Tsonis PA: Bridging the regeneration gap: genetic insights from diverse animal models. Nature Rev Genet 2006, 7:873-883.

2. Sánchez Alvarado A: Planarian regeneration: its end is its beginning. Cell 2006, 124:241-5.

3. Saló E, Abril JF, Adell T, Cebrià F, Eckelt K, Fernandez-Taboada E, HandbergThorsager M, Iglesias M, Molina MD, Rodríguez-Esteban G: Planarian regeneration: achievements and future directions after 20 years of research. Int J Dev Biol 2009, 53:1317-1327.

4. Brockes JP: Amphibian limb regeneration: rebuilding a complex structure. Science 1997, 276:81-87.

5. Brockes JP, Kumar A: Plasticity and reprogramming of differentiated cells in amphibian regeneration. Nature Rev 2002, 3:566-574.

6. Hyman LH: The Invertebrates: Echinodermata. McGraw-Hill, New York; 19554.

7. García-Arrarás JE, Estrada-Rodgers L, Santiago R, Torres II, Díaz-Miranda L, Torres-Avillán I: Cellular mechanisms of intestine regeneration in the sea cucumber, Holothuria glaberrima. J Exp Zool 1998, 281:288-304.

8. García-Arrarás JE, Schenk C, Rodrígues-Ramírez R, Torres II, Valentín G, Candelaria AG: Spherulocytes in the echinoderm Holothuria glaberrima and their involvement in intestinal regeneration. Dev Dyn 2006, 235:3259-3267.

9. Quiñones JL, Rosa R, Ruiz DL, García-Arrarás JE: Extracellular matrix remodeling involvement during intestine regeneration in the sea cucumber Holothuria glaberrima. Dev Biol 2002, 250:181-197. 
10. Candelaria AG, Murray G, File SK, García-Arrarás JE: Contribution of mesenterial muscle dedifferentiation to intestine regeneration in the sea cucumber Holothuria glaberrima. Cell Tissue Res 2006, 325:55-65.

11. Dupont S, Thorndyke MC: Growth or differentiation? Adaptive regeneration in the brittlestar Amphiura filiformis. J Exp Biol 2006, 209:3873-81.

12. García-Arrarás JE, Dolmatov IY: Echinoderms: potential model systems for studies on muscle regeneration. Curr Pharm Des 2010, 16:942-955.

13. Kondo M, Akasaka K: Regeneration in crinoids. Dev Growth Differ 2010, 52:57-68.

14. Bode HR: Axial patterning in hydra. Cold Spring Harb Perspect Biol 2009, 1: a000463.

15. Galliot B, Miljkovic-Licina M, de Rosa R, Chera S: Hydra, a niche for cell developmental plasticity. Semin Cell Dev Biol 2006, 17:492-502.

16. Galliot B, Ghila L: Cell plasticity in homeostasis and regeneration. Mol Reprod Dev 2010, 77:837-55.

17. Beck CW, Izpisúa Belmonte JC, Christen B: Beyond early development: Xenopus as an emerging model for the study of regenerative mechanisms. Dev Dyn 2009, 238:1226-48.

18. Suárez-Castillo E, Medina-Ortíz W, Roig-López JL, García-Arrarás JE: Ependymin, a gene involved in regeneration and neuroplasticity is overexpressed during regeneration in the echinoderm Holothuria glaberrima. Gene 2004, 334:133-143.

19. Rojas-Cartagena C, Ortíz-Pineda P, Ramírez-Gómez F, Suárez-Castillo EC, Matos-Cruz V, Rodríguez C, Ortíz-Zuazaga H, García-Arrarás JE: Distinct profiles of expressed sequence tags during intestinal regeneration in the sea cucumber Holothuria glaberrima. Physiol Genomics 2007, 31:203-215.

20. Ortiz-Pineda PA, Ramírez-Gómez F, Pérez-Ortiz J, González-Díaz S, SantiagoDe Jesús F, Hernández-Pasos J, Del Valle-Avila C, Rojas-Cartagena C, SuárezCastillo EC, Tossas K, Méndez-Merced AT, Roig-López JL, Ortiz-Zuazaga H, García-Arrarás JE: Gene expression profiling of intestinal regeneration in the sea cucumber. BMC Genomics 2009, 10:262.

21. Mashanov VS, Zueva OR, Rojas-Cartagena C, García-Arrarás JE: Visceral regeneration in a sea cucumber involves extensive expresion of survivin and mortalin homologs in the mesothelium. BMC Dev Biol 2010, 10:117.

22. Rieger RM, Lombardi J: Ultrastructure of the coelomic lining in echinoderm podia: significance for concepts in the evolution of muscle and peritoneal cells. Zoomorphol 1987, 10(7):191-208.

23. Murray G, García-Arrarás JE: Myogenesis during holothurian intestinal regeneration. Cell Tissue Res 2004, 318:515-524.

24. Dolmatov IY, Ginanova TT: Muscle regeneration in holothurians. MicrosC Res Tech 2001, 55:452-463.

25. Mashanov VS, Dolmatov IY, Heinzeller T: Transdifferentiation in holothurian gut regeneration. Biol Bull 2005, 209:184-193.

26. Dolmatov IY, Eliseikina MG, Bulgakov AA, Ginanova TT, Lamash NE, Korchagin VP: Muscle regeneration in the holothurian Stichopus japonicus. Roux's Arch Dev Biol 1996, 205:486-93.

27. VandenSpiegel D, Jangoux M, Flammang P: Maintaining the line of defense: Regeneration of Cuvierian tubules in the sea cucumber Holothuria forskali (Echinodermata, Holothuroidea). Biol Bull 2000, 198:34-49.

28. Candia-Carnevali MD, Bonasoro F, Lucca E, Thorndyke MC: Pattern of cell proliferation in the early stages of arm regeneration in the feather star Antedon mediterranea. J Exp Zool 1995, 272:464-474.

29. Candia-Carnevali MD, Bonasoro F, Lucca E, Thorndyke MC: Pattern of cell proliferation in the advanced stages of arm regeneration in the feather star Antedon mediterranea. Cell Tissue Res 1997, 289:363-374.

30. Moss C, Hunter AJ, Thorndyke MC: Patterns of bromodeoxyuridine incorporation and neuropeptide immunoreactivity during arm regeneration in the starfish Asterias rubens. Philos Trans $R$ Soc London $B$ 1998, 353:421-436

31. Carlson BM: Principles of regenerative Biology. Academic Press, NY; 2007 34-42.

32. Yamada T: Control mechanisms in cell-type conversion in newt lens regeneration. Basel Switzerland: Karger; 1977.

33. Satoh A, Graham GM, Bryant SV, Gardiner DM: Neurotrophic regulation of epidermal dedifferentiation during wound healing and limb regeneration in the axolotl (Ambystoma mexicanum). Dev Biol 2008, 319:321-335, 2008
34. Hay ED: Microscopic observations of muscle dedifferentiation in regenerating Amblyostoma limbs. Dev Biol 1959, 1:555-585.

35. Kragl M, Knapp D, Nacu E, Khattak S, Maden M, Epperlein HH, Tanaka EM: Cells keep a memory of their tissue origin during axolotl limb regeneration. Nature 2009, 460:60-65.

36. Knof F, Hammond C, Chekuru A, Kurth T, Hans S, Weber CW, Mahatma G, Fisher S, Brand M, Schulte-Merker S, Weidinger G: Bone regenerates via dedifferentiation of osteoblasts in the zebrafish fin. Dev Cell 2011 20:713-724.

37. Tu S, Johnson SL: Fate restriction in the growing and regenerating zebrafish fin. Dev Cell 2011, 20:725-732.

38. Poss KD, Keating MT, Nechiporuk A: Tales of regeneration in zebrafish. Dev Dyn 2003, 226:202-210.

39. Hay ED: The mesenchymal cell, its role in the embryo, and the remarkable signaling mechanisms that create it. Dev Dyn 2005, 233:706-720.

40. Kalluri R: EMT: When epithelial cells decide to become mesenchymal-like cells. J Clin Inv 2009, 119:1417-1419.

41. Poleo G, Brown CW, LaForest L, Akimenko MA: Cell proliferation and movement during early fin regeneration in zebrafish. Dev Dyn 2001, 221:380-390

42. Santos-Ruiz L, Santamaria JA, Ruiz-Sánchez J, Becerra J: Cell proliferation during blastema formation in the regenerating teleost fin. Dev Dyn 2002, 223:262-272

43. Mozzi D, Dolmatov IY, Bonasoro F, CandiaCarnevali MD: Visceral regeneration in the crinoid Antedon mediterranea: basic mechanisms, tissues and cells involved in gut regrowth. Central European J Biol 2006, 1:609-635

44. Poss KD, Wilson LG, Keating MT: Heart regeneration in zebrafish. Science 2002, 298:2188-2190.

45. Lepilina A, Coon AN, Kikuchi K, Holdway JE, Roberts RW, Burns CG, Poss KD: A dynamic epicardial injury response supports progenitor cell activity during zebrafish heart regeneration. Cell 2006, 127:607-619.

46. Akimenko MA, Mari-Beffa M, Becerra J, Geraudie J: Old questions, new tools, and some answers to the mystery of fin regeneration. Dev Dyn 2003, 226:190-201.

47. Sánchez Alvarado A, Kang H: Multicellularity, stem cells, and the neoblasts of the planarian Schmidtea mediterranea. Exp Cell Res 2005, 306:299-308

48. Candia-Carnevali MD: Regeneration in Echinoderms: repair, regrowth, cloning. ISJ 2006, 3:64-76.

49. Bannister R, McGonnell IM, Graham A, Thorndyke MC, Beesley PW: Afuni, a novel transforming growth factor-beta gene is involved in arm regeneration by the brittle star Amphiura filiformis. Dev Genes Evol 2005, 215:393-401.

50. Biressi ACM, Zou T, Dupont S, Di Benedetto C, Bonasoro F, Thorndyke MC, Candia Carnevali MD: Wound healing and arm regeneration in Ophioderma longicaudum and Amphiura filiformis (Ophiuroidea, Echinodermata): comparative morphogenesis and histogenesis. Zoomorphol 2010, 129:1-19.

51. Mladenov PV, Bisgrove B, Asotra S, Burke R: Mechanisms of the arm-tip regeneration in the sea star, Leptasterias hexactis. Roux's Arch Dev Biol 1989, 198:19-28

52. García-Arrarás JE, Greenberg MC: Visceral regeneration in holothurians. Microsc Res Tech 2001, 55:438-451.

53. Bossche JP, Jangoux M: Epithelial origin of starfish coelomocytes. Nature 1979, 261:227-228

54. Leibson NL: Regeneration of digestive tube in holothurians Stichopus japonicus and Eupentacta fraudatrix. Monogr Dev Biol 1992, 23:51-61.

55. San Miguel-Ruiz JE, García-Arrarás JE: Common cellular events occur during wound healing and organ regeneration in the sea cucumber Holothuria glaberrima. BMC Dev Biol 2007, 7:115.

56. Harlow E, Lane D: Antibodies: A Laboratory Manual. Cold Spring Harbor Laboratory, Cold Spring Harbor, NY; 1988.

57. Díaz-Balzac CA, Abreu-Arbelo JE, García-Arrarás JE: Neuroanatomy of the tube feet and tentacles in Holothuria glaberrima (Holothuroidea, Echinodermata). Zoomorphology. 2010, 129:33-43.

doi:10.1186/1471-213X-11-61

Cite this article as: García-Arrarás et al: Cell dedifferentiation and epithelial to mesenchymal transitions during intestinal regeneration in H. glaberrima. BMC Developmental Biology 2011 11:61. 